\title{
Heat Transfer and Entropy Generation Evaluation on Molten Salt Tank Foundation with Internal Water Cooling
}

\author{
Shien Sun ${ }^{1}$, Haihua Luo ${ }^{1}$, Basher Hassan Al-Kbodi ${ }^{2, *}$, Qiang Shen ${ }^{3}$, and Houlei Zhang ${ }^{2}$ \\ ${ }^{1}$ Zhejiang Zheneng Technology Institute, Hangzhou, 311100, China \\ ${ }^{2}$ Nanjing University of Science and Technology, Nanjing, 210094, China \\ ${ }^{3}$ Zhejiang Zheneng Jiaxing Power Plant Co Ltd, Jiaxing, 314000, China
}

\begin{abstract}
Molten salt tanks are used to store and release thermal energy. Large heat leakage through the molten salt tank foundation to the ground and high temperature of the foundation are detrimental to long-term operation safety. Here we evaluate the heat transfer and entropy generation characteristics of molten salt tank foundations with internal water cooling. Both laminar and turbulent flows reduce the heat leakage efficiently, while the power consumption for the laminar flow is negligible. The effects of the geometrical parameters are presented. Internal fins in the cooling channels decrease the heat leakage significantly. The total entropy generation rate with foundation cooling is higher than that without foundation cooling. The entropy generation rate in the solid domain is much larger than that in the fluid domain and the flow friction irreversibility is tiny. Larger insulation layer thickness decreases the heat leakage and the total entropy generation rate simultaneously. The local entropy generation rate map helps us identify where the most irreversibility is produced. The largest local entropy generation rate for the design with foundation cooling occurs near the solid-fluid interfaces and is much higher than that without foundation cooling.
\end{abstract}

\section{Introduction}

Energy storage is essential whenever there is a mismatch between the supply and demand of energy. Thermal energy storage (TES) is a technology that stores thermal energy in one duration by heating or cooling a storage medium so that the stored energy can be used in another duration. Various TES techniques have been developed over the past decades ${ }^{[1-3]}$. The classification of energy storage and the materials used have been detailed by some researchers, e.g., Sarbu and Sebarchievici ${ }^{[3]}$. In high temperature materials processing industries and solar thermal power plants (i.e., concentrated solar power), molten salts are commonly used as working fluids for heat storage and heat transfer ${ }^{[4,5]}$. For example, Hitec salt is commercially utilized due to its low cost, high heat transfer coefficient, thermal stability and low melting point $\left(142^{\circ} \mathrm{C}\right)^{[6]}$. Molten salt tank, which stores thermal energy, is a critical component in TES systems, either one-tank or two-tank systems. Heat loss of molten salt tank will drop the efficiency of the applications. Molten salt tank foundation, which bears the weight of the tank, is crucial to the operation safety of the tank. On one side, high temperature in the concrete of the foundation beyond its allowable value is dangerous from the viewpoint of strength. On the other side, for long-term operation, the heat loss through the foundation (even small amount) may be accumulated in the ground and therefore threaten the stability of the foundation. So properly designed thermal control of the foundation (e.g., insulation, cooling) is necessary.

In the early time of solar thermal power generation technology, the total heat loss of the molten salt tank was reported for a few plants, such as CESA-1, Solar I and Solar II ${ }^{[7-9]}$. Recently, some works have been presented in the modelling and test of molten salt tanks involving the heat loss through the foundation.

Schulte-Fischedick et al ${ }^{[10]}$ simulated a two-tank 880 MWh molten salt storage system by using CFD technique. Heat conduction into the concrete foundation and the soil is modelled as conduction into a semi-infinite body. The results reveal that the heat loss through the foundation is independent upon the liquid level in the tank and cannot be neglected. At the lower edges of the tank, there generates high heat loss flux.

Gabbrielli and Zamparelli ${ }^{[11]}$ proposed an optimal design of a molten salt thermal storage tank based on the minimization of the total investment cost of the storage system. The case study of a $600 \mathrm{MWh}$ storage system shows that an internally insulated carbon steel storage system is about $20 \%$ cheaper than that of $321 \mathrm{H}$ stainless steel storage system without internal insulation. Water cooling of the foundation was considered to control the temperature of the concrete, although the calculation details were not reported. Zaversky et al ${ }^{[12]}$ built a transient model using Modelica, which describes the transient loss of molten salt tanks. Natural convective air cooling ducts in the foundation are designed, but for simplicity, in the calculation of the heat loss through the

\footnotetext{
* Corresponding author: alkbodi@njust.edu.cn (B. H. Al-Kbodi)
} 
foundation, the bottom end insulation layer temperature is set as constant $\left(90^{\circ} \mathrm{C}\right)$. The results show that the heat loss through the foundation accounts for a large proportion in the total heat loss. Rodríguez et al. ${ }^{[13]}$ proposed a parallel modular object-oriented methodology for the resolution of molten salt tanks. Different elements including the tank foundation are considered as independent systems. Passive cooling in the foundation was taken into account although its details were not presented. The heat losses for Andasol two-tank system were evaluated.

For a pilot molten salt tank with $1.2 \mathrm{~m}$ diameter and $0.5 \mathrm{~m}$ cylinder height, Prieto et al. ${ }^{[14]}$ presented the experimental evaluation of the temperature distribution inside the tank and the heat losses. The results reveal that at the bottom and near the wall, the salt temperature is lower and no stratification is found. The heat losses are from $61 \mathrm{~W} / \mathrm{m}^{2}$ through the bottom to $80 \mathrm{~W} / \mathrm{m}^{2}$ through the walls. Prieto et al ${ }^{[15]}$ further reported the heat losses of a two-tank molten salt pilot plant with 8.1 MWhth built in Spain. Each molten salt tank has $8 \mathrm{~m}$ diameter and $4.4 \mathrm{~m}$ cylinder height. The experimental results conclude that insulation, mechanical assembly and foundation are the keys to the feasibility of a TES system. Bonilla et al. ${ }^{[16]}$ developed a dynamic thermal energy tank model, which was validated by experimental data from CIEMAT-PSA molten salt testing facility. The heat losses under three conditions (i.e., at rest, charging and discharging processes) were discussed. Zhang et al. ${ }^{[17]}$ performed an experimental study for a lab-scale molten salt tank with $1.2 \mathrm{~m}$ diameter and $1 \mathrm{~m}$ cylinder height. The results show that the temperature stratification occurs at the bottom of the tank with a height of $200 \mathrm{~mm}$. The heat loss per unit area for the roof, wall and bottom is similar. The temperature stratification reduces the heat loss through the foundation by increasing the thermal resistance.

Although the present paper focuses on the heat loss (i.e., heat transfer) aspect of molten salt tanks, the thermal-related mechanical performance of the foundation is also critical. Wan et al. ${ }^{[18]}$ evaluated the thermal and mechanical performance of a high temperature molten salt tank. Temperature distribution, heat loss and stress were documented. The results show that the temperature of the foundation is high and nonuniform and foundation cooling is necessary. The flow direction of the cooling air should be from the center to the outer part.

In the temperature range $300-600^{\circ} \mathrm{C}$ (cf. the abovementioned references), nitrite salt such as Solar salt, Hitec salt, is commercially mature and widely used. For those fields with higher temperature, although not mature, there are some researches. For example, Prieto et al. ${ }^{[19]}$ reported a carbonate molten salt solar thermal pilot facility up to $700^{\circ} \mathrm{C}$. The molten salt tank has $2 \mathrm{~m}$ diameter and 0.874 $\mathrm{m}$ cylinder height. With the increase of the salt temperature, the heat losses rise. At $700^{\circ} \mathrm{C}$, the measured heat losses through the walls, roof and foundation are 147 , 199 and $256 \mathrm{~W} / \mathrm{m}^{2}$, respectively.

From the above brief review, we realize that although the heat loss through the foundation has been investigated and the foundation cooling was also taken into account by some researchers, public studies of the foundation cooling (active or passive) itself are still limited ${ }^{[11,13,18]}$. In this paper, we first present laminar flow water cooling performance of a molten salt tank foundation based on CFD simulations; then we study three cooling enhancement methods, i.e., internal fins, thicker insulation layer and turbulent flow. Besides the first lawbased heat transfer analysis, total and local entropy generation rates will be documented for identifying the irreversibilities in the foundation cooling process. The work in this paper will provide reference for the foundation design of high temperature molten salt tanks.

\section{Physical model}

Consider a lab-scale molten salt tank foundation with three layers, i.e., carbon steel, insulation layer and concrete, shown in Figure 1. Parallel water cooling channels (smooth round ducts) are set in the mid position of the y direction of the concrete. For the design without the water cooling, heat is transferred from the top surface with the temperature of the molten salt to the bottom surface with the temperature of the ground. For the design with the water cooling, water removes heat from the concrete to the outside surrounding, so the heat leakage to the foundation is reduced. The design object becomes minimizing the heat leakage $\left(\dot{Q}_{2}\right)$ or maximizing the heat removal from the foundation $\left(\dot{Q}_{w}\right)$. The function of the water cooling here is equivalent to that of the foundation insulation. Some geometric parameters used in this paper are as follows: $W=7000 \mathrm{~mm}, L=5600 \mathrm{~mm}, H_{l}=40 \mathrm{~mm}$, $H_{2}=500 \mathrm{~mm}$ (except in Figures 17-19), $H_{3}=500 \mathrm{~mm}, D_{l}$ $=5000 \mathrm{~mm}$.

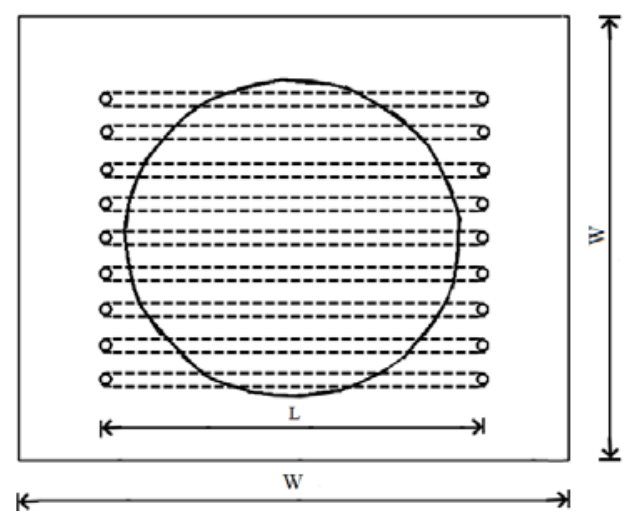

(a)

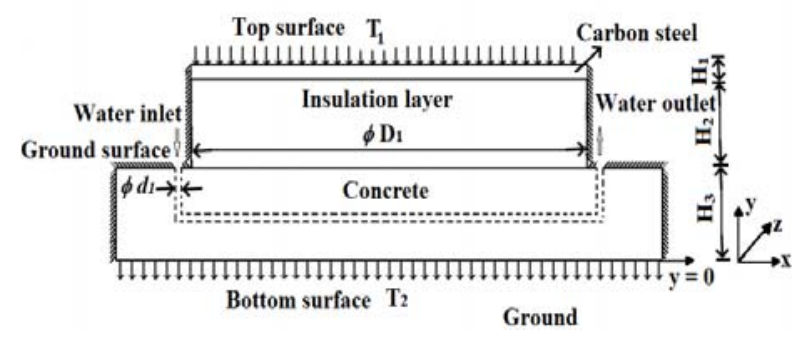

(b) 
Fig. 1. Molten salt tank foundation with parallel water cooling channels (drawn not in proportion): (a) top view; (b) view along $\mathrm{z}$ direction.

\section{Numerical model}

For long-term operation, the power consumption driving the water flow affects the economy of the cooling system. For reducing the power consumption, we start our analysis from low speed flow. We assume that the water flow is steady incompressible laminar flow with constant properties. Larger volume of the fluid domain $\left(V_{f}\right)$ means smaller flow resistance, which is good for heat transfer. But it weakens the concrete strength, so trade-off is necessary. Here we select the volume of the cooling channels as a constraint.

$$
V_{f}=f(d, n)
$$

where $V_{f}$ is the volume of the cooling channels, $\mathrm{m}^{3} ; d$ is the diameter of the cooling channels, $\mathrm{mm} ; n$ is the number of the cooling channels.

The governing equations for the fluid are as follows

$$
\begin{gathered}
\frac{\partial u}{\partial x}+\frac{\partial v}{\partial y}+\frac{\partial w}{\partial z}=0 \\
u \frac{\partial u}{\partial x}+v \frac{\partial u}{\partial y}+w \frac{\partial u}{\partial z}=-\frac{1}{\rho} \frac{\partial P}{\partial x}+v\left(\frac{\partial^{2} u}{\partial x^{2}}+\frac{\partial^{2} u}{\partial y^{2}}+\frac{\partial^{2} u}{\partial z^{2}}\right) \\
u \frac{\partial v}{\partial x}+v \frac{\partial v}{\partial y}+w \frac{\partial v}{\partial z}=-\frac{1}{\rho} \frac{\partial P}{\partial y}+v\left(\frac{\partial^{2} v}{\partial x^{2}}+\frac{\partial^{2} v}{\partial y^{2}}+\frac{\partial^{2} v}{\partial z^{2}}\right) \\
u \frac{\partial w}{\partial x}+v \frac{\partial w}{\partial y}+w \frac{\partial w}{\partial z}=-\frac{1}{\rho} \frac{\partial P}{\partial z}+v\left(\frac{\partial^{2} w}{\partial x^{2}}+\frac{\partial^{2} w}{\partial y^{2}}+\frac{\partial^{2} w}{\partial z^{2}}\right) \\
u \frac{\partial T}{\partial x}+v \frac{\partial T}{\partial y}+w \frac{\partial T}{\partial z}=\alpha\left(\frac{\partial^{2} T}{\partial x^{2}}+\frac{\partial^{2} T}{\partial y^{2}}+\frac{\partial^{2} T}{\partial z^{2}}\right)
\end{gathered}
$$

where $u, v, w$ are the velocity components in $x, y, z$ directions, $\mathrm{m} / \mathrm{s} ; x, y, z$ are the coordinates, $\mathrm{mm} ; \quad P$ is pressure, $\mathrm{Pa} ; \rho$ is density, $\mathrm{kg} / \mathrm{m}^{3} ; T$ is temperature, $\mathrm{K} ; \alpha$ is thermal diffusivity, $\mathrm{m}^{2} / \mathrm{s}$.

The energy equation for the solid is

$$
\left(\frac{\partial^{2} T_{s}}{\partial x^{2}}+\frac{\partial^{2} T_{s}}{\partial y^{2}}+\frac{\partial^{2} T_{s}}{\partial z^{2}}\right)=0
$$

By invoking the first and second laws of thermodynamics, the total entropy generation rate can be derived as follows ${ }^{[20]}$.

$$
\dot{S}_{g, \text { Total }}=\frac{\dot{Q}_{2}}{T_{2}}-\frac{\dot{Q}_{1}}{T_{1}}+\dot{m}\left(s_{\text {out }}-s_{\text {in }}\right)
$$

where $\dot{S}_{g, \text { Total }}$ is the total entropy generation rate, W/K; $\dot{Q}_{2}$ is the heat leakage, $\mathrm{W} ; T_{2}$ is the temperature at the bottom surface, $\mathrm{K} ; \dot{Q}_{1}$ is the heat transfer rate at the top surface, $\mathrm{W} ; T_{1}$ is the temperature at the top surface, $\mathrm{K}$; $\dot{m}$ is mass flow rate, $\mathrm{kg} / \mathrm{s} ; s$ is specific entropy, $\mathrm{J} /(\mathrm{kgK})$. In Eq. (8), $\dot{m}\left(s_{\text {out }}-s_{\text {in }}\right)$ is positive as the water cooling removes heat from the foundation. For the design without the cooling channels (also called the reference design), $\dot{m}\left(s_{\text {out }}-s_{\text {in }}\right)$ is zero.

Based on the flow and temperature fields, the local entropy generation rate is obtained based on Bejan's work $^{[20]}$

$$
\begin{aligned}
& \dot{s}_{g}^{\prime \prime \prime}=\frac{k}{T^{2}}\left[\left(\frac{\partial T}{\partial x}\right)^{2}+\left(\frac{\partial T}{\partial y}\right)^{2}+\left(\frac{\partial T}{\partial z}\right)^{2}\right]+ \\
& \frac{\mu}{T}\left\{2\left[\left(\frac{\partial u}{\partial x}\right)^{2}+\left(\frac{\partial v}{\partial y}\right)^{2}+\left(\frac{\partial w}{\partial z}\right)^{2}\right]+\left(\frac{\partial u}{\partial y}+\frac{\partial v}{\partial x}\right)^{2}\right. \\
& \left.+\left(\frac{\partial u}{\partial z}+\frac{\partial w}{\partial x}\right)^{2}+\left(\frac{\partial v}{\partial z}+\frac{\partial w}{\partial y}\right)^{2}\right\}
\end{aligned}
$$

where $\dot{s}_{g}^{\prime \prime \prime}$ is the local entropy generation rate, $\mathrm{W} /\left(\mathrm{m}^{3} \mathrm{~K}\right)$; $k$ is thermal conductivity, $\mathrm{W} /(\mathrm{mK}) ; \mu$ is dynamic viscosity, $\mathrm{kg} /(\mathrm{ms})$. The entropy generation rates of the fluid domain and the solid domain are then calculated respectively via integration:

$$
\begin{aligned}
& \dot{S}_{g, \text { Fluid }}=\int_{V_{\text {Fluid }}} \dot{S}_{\text {gen }}^{\prime \prime \prime} d x d y d z \\
& \dot{S}_{g, \text { Solid }}=\int_{V_{\text {Solid }}} \dot{S}_{\text {gen }}^{\prime \prime \prime} d x d y d z
\end{aligned}
$$

where $\dot{S}_{g, \text { Fluid }}$ is the entropy generation rate for the fluid domain, $\mathrm{W} / \mathrm{K} ; \dot{S}_{g, \text { Solid }}$ is the entropy generation rate for the solid domain, $\mathrm{W} / \mathrm{K}$. The total entropy generation rate [cf. Equation (8)] can be obtained in another way, i.e., by summing Equations (10) and (11):

$$
\dot{S}_{g, \text { Total }}=\dot{S}_{g, \text { Fluid }}+\dot{S}_{g, \text { Solid }}
$$

In the fluid domain, the pressure drop-induced entropy generation (i.e., flow friction irreversibility) is given by

$$
\dot{S}_{g, F l u i d, \Delta P}=\dot{m} \frac{\alpha_{V} \Delta P}{\rho}
$$

where $\dot{S}_{g, F l u i d, \Delta P}$ is the flow friction irreversibility, W/K; $\alpha_{V}$ is thermal expansion coefficient, $1 / \mathrm{K} ; \Delta P$ is pressure drop, Pa. The temperature difference-induced entropy generation (i.e., heat transfer irreversibility) is

$$
\dot{S}_{g, \text { Fluid }, \Delta T}=\dot{S}_{g, \text { Fluid }}-\dot{S}_{g, \text { Fluid }, \Delta P}
$$

To evaluate the work penalty of the water cooling, we define the first law-based heat-to-work ratio as follows.

$$
\beta=\frac{\dot{Q}_{2}}{\dot{W}}=\frac{\dot{Q}_{2}}{\dot{m} \Delta P / \rho}
$$

where $\beta$ is the heat-to-work ratio; $\dot{W}$ is the power consumption, W. Larger $\beta$ means better cooling performance (i.e., larger heat removal per unit power consumption). 
Except laminar flow cooling, we will further analyse three ways of cooling enhancement:

I. Incorporate internal fins in the cooling channels (cf. an example shown in Figure 2);

II. Increase the thickness of the insulation layer;

III. Increase the water flow rate (turbulent flow).

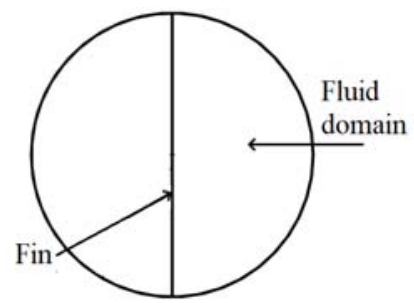

Fig. 2. Cross section of one cooling channel with internal fin.

For the design with fins, the energy equation for the solid domain should include the fins. For turbulent flow, we adopt standard k- $\varepsilon$ model that has been widely used for single-phase flow simulations. The governing equations can be found in many textbooks or papers (e.g., [21]) which are not listed here.

The boundary conditions and the physical properties are illustrated in Table 1 and Table 2 respectively.

Table 1. The boundary conditions.

\begin{tabular}{|c|c|c|}
\hline \multicolumn{3}{|c|}{ Boundary Condition } \\
\hline Fluid & Inlet & $20^{\circ} \mathrm{C}, \dot{m}$ \\
\cline { 2 - 3 } & Outlet & $P=0 \mathrm{~Pa}$ (gauge) \\
\hline \multirow{3}{*}{ Solid } & Top surface & $420^{\circ} \mathrm{C}$ \\
\cline { 2 - 3 } & $\begin{array}{c}\text { Ground surface, side } \\
\text { surfaces }\end{array}$ & Adiabatic \\
\cline { 2 - 3 } & Bottom surface & $20^{\circ} \mathrm{C}$ \\
\hline
\end{tabular}

Table 2. Physical properties ${ }^{[22,23]}$

\begin{tabular}{|c|c|c|c|c|c|}
\hline Property & $\begin{array}{c}\text { Density } \\
\rho\left(\mathrm{kg} / \mathrm{m}^{3}\right)\end{array}$ & $\begin{array}{c}\text { Specific heat } \\
\text { at constant } \\
\text { pressure } \\
c_{p}[\mathrm{~J} /(\mathrm{kgK})]\end{array}$ & $\begin{array}{c}\text { Thermal } \\
\text { conductivity } \\
k[\mathrm{~W} /(\mathrm{mK})]\end{array}$ & $\begin{array}{c}\text { Dynamic } \\
\text { viscosity } \\
\mu[\mathrm{kg} /(\mathrm{ms})]\end{array}$ & $\begin{array}{c}\text { Expansion } \\
\text { coefficient } \\
\alpha_{v}(1 / \mathrm{K})\end{array}$ \\
\hline Water & 998 & 4182 & 0.6 & 0.001003 & 0.00021 \\
\hline Carbon steel & 7850 & 502.4 & 54 & & \\
\hline Insulation layer (Firebrick) & 2000 & 1000 & 1 & & \\
\hline
\end{tabular}

The flow and temperature fields are solved by ANSYS Fluent software ${ }^{[24]}$. The residuals of the continuity equation, the moment equation and the energy equation are set as $10^{-6}$. The heat removal $\dot{Q}_{w}$ and the pressure drop $\triangle P$ are calculated as the objectives of grid independence checking. The difference less than $1 \%$ between two adjacent meshes is thought as acceptable. Then, the velocity and temperature gradients are extracted from the flow and heat transfer simulation results, and the custom field function in ANSYS Fluent software ${ }^{[24]}$ is used to obtain the local entropy generation rate according to Equation (9). For the laminar flow in Sections 4.1 to 4.4, the Reynolds number at the inlet of the cooling channels is in the range from 12.6 to 952 . So, the laminar flow assumption is appropriate. For the turbulent flow in Section 4.5, the Reynolds number will also be reported (cf. Section 4.5).

\section{Results and Discussion}

\subsection{Effects of variable $V_{f}$}

For the reference design, the heat leakage and the entropy generation rate only depend on the temperatures of the top surface and the bottom surface, which are $\dot{Q}_{10}=\dot{Q}_{20}=$
$8278 \mathrm{~W}$ and $\dot{S}_{g 0, \text { Total }}=16.27 \mathrm{~W} / \mathrm{K}$. For the design with the cooling channels, there are two ways to vary $V_{f}$ : increase the diameter $d$ and the number $n$ of the channels. Figure 3 shows the effects of the flow rate $\dot{m}$ on the heat leakage $\dot{Q}_{2}$ and the heat removal $\dot{Q}_{w}$ with $n=17$ for three different diameters. When $\dot{m}$ is small, $\dot{Q}_{w}$ increases and $\dot{Q}_{2}$ drops significantly with the increasing in $\dot{m}$. When $\dot{m}$ is large, $\dot{Q}_{w}$ and $\dot{Q}_{2}$ change slowly with the increasing in $\dot{m}$. When $\dot{m}$ is very small, the effects of $d$ on $\dot{Q}_{w}$ and $\dot{Q}_{2}$ are negligible. When $\dot{m}$ is large, larger $d$ enhances the cooling heat transfer because of larger cooling area $A$ (and $V_{f}$ ) and less thermal resistance of the concrete (equivalent to larger temperature difference). In fact, the water cooling behaves as an insulation tool to prevent the heat transfer from the top surface $\left(T_{1}\right)$ to the bottom surface $\left(T_{2}\right)$. According to Figure 3, in order to achieve proper cooling effect, $\dot{m}$ should be larger than some value, like $0.2 \mathrm{~kg} / \mathrm{s}$, in which case $\dot{Q}_{2}$ is much less than $\dot{Q}_{20}$. It should be noted that $\dot{Q}_{1}$ is not the same as $\dot{Q}_{10}$ due to the incorporation of the foundation cooling. In Figure $3, \dot{Q}_{1}>$ $\dot{Q}_{10}$. Figure 4 shows that for smaller diameter channels, due to larger velocity, the power consumption is higher than that for larger diameter channels. Nevertheless, in the 
present range, the heat-to-work ratio $\beta$ is very large. For example, when $\dot{m}=0.068 \mathrm{~kg} / \mathrm{s}$ and $d=40 \mathrm{~mm}, \beta=$ $1.2668 \times 10^{8}$, so the power consumption is negligible.

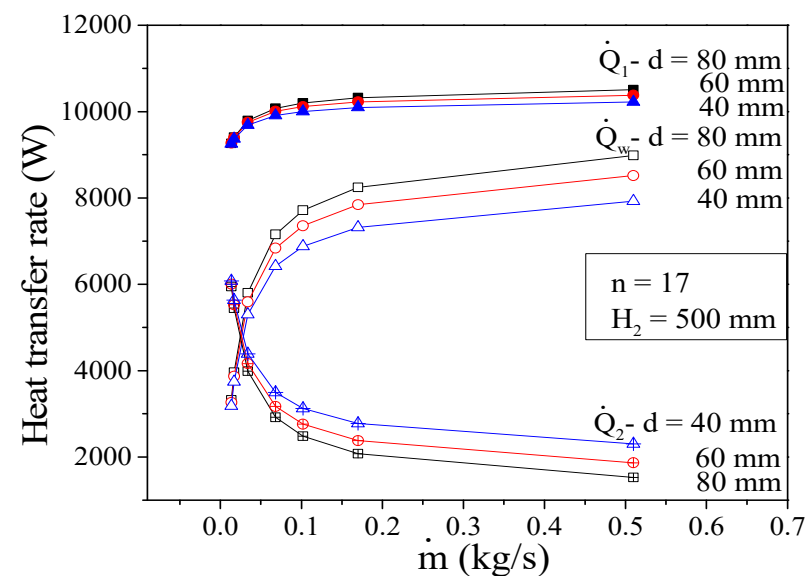

Fig. 3. Heat transfer rate with $n=17$ and variable $V_{f}$.

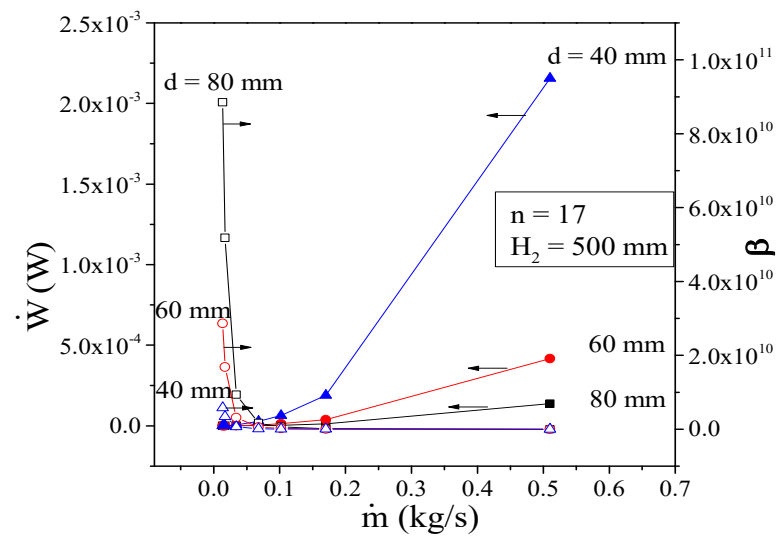

Fig. 4. Power consumption and heat-to-work ratio with $n=17$ and variable $V_{f}$.

Figure 5 shows that the total entropy generation rate $\dot{S}_{g, \text { Total }}$ increases with the increasing in $\dot{m}$. When $\dot{m}$ is large, $\dot{S}_{g, \text { Total }}$ changes slowly. In the range in Figure 5, $\dot{S}_{g, \text { Total }}$ is greater than $\dot{S}_{g 0, \text { Total }}$. Here the diameter $d$ of the cooling channels nearly does not influence $\dot{S}_{g, \text { Total }}$. From Equation (8), we have known that $\dot{S}_{g, \text { Total }}$ depends on three terms: $\frac{\dot{Q}_{2}}{T_{2}} \frac{\dot{Q}_{1}}{T_{1}}$ and $\dot{m}\left(s_{\text {out }}-s_{\text {in }}\right)$. When the water cooling is enhanced, all these three terms will change: $\frac{\dot{Q}_{2}}{T_{2}}$ drops and $\dot{m}\left(s_{\text {out }}-s_{\text {in }}\right)$ rises. Due to the incorporation of the water cooling, $\dot{Q}_{1}$ (or $\frac{\dot{Q}_{1}}{T_{1}}$ ) also changes. From Figure 5 , we also see that the entropy generation rate in the solid domain ( $\dot{S}_{g, \text { Solid }}$ ) is dominant. The gap between the $\dot{S}_{g, \text { Total }}$ curve and the $\dot{S}_{g, \text { Solid }}$ curve corresponds to $\dot{S}_{g, \text { Fluid }}$ which is significantly less than $\dot{S}_{g, \text { Solid }}$. Here the flow friction irreversibility ( $\dot{S}_{g, \text { Fluid, } \Delta P}$ ) is less than $10^{-4} \mathrm{~W} / \mathrm{K}$ and completely negligible. In the fluid domain, only the heat transfer irreversibility is important.

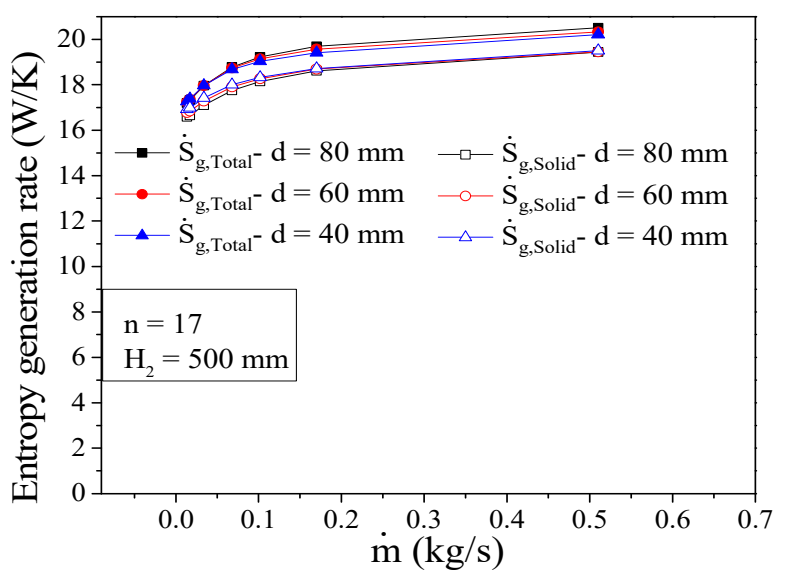

Fig. 5. Entropy generation rate with $n=17$ and variable $V_{f}$.

Figures 6 to 8 show the effects of $n$ for fixed $\dot{m}$ (= $0.068 \mathrm{~kg} / \mathrm{s}$ ). Figures 6 and 7 show that under the given conditions, larger $n$ (also larger $V_{f}$ ) can decrease $\dot{Q}_{2}$ and $\dot{W}$ simultaneously. This conclusion attributes to the increased heat transfer area, decreased thermal resistance of the concrete and larger cross section area of the cooling channels. For the specified $\dot{m}$, the effects of $n$ on $\dot{S}_{g, \text { Total }}$ and $\dot{S}_{g, \text { Solid }}$ are quite weak.

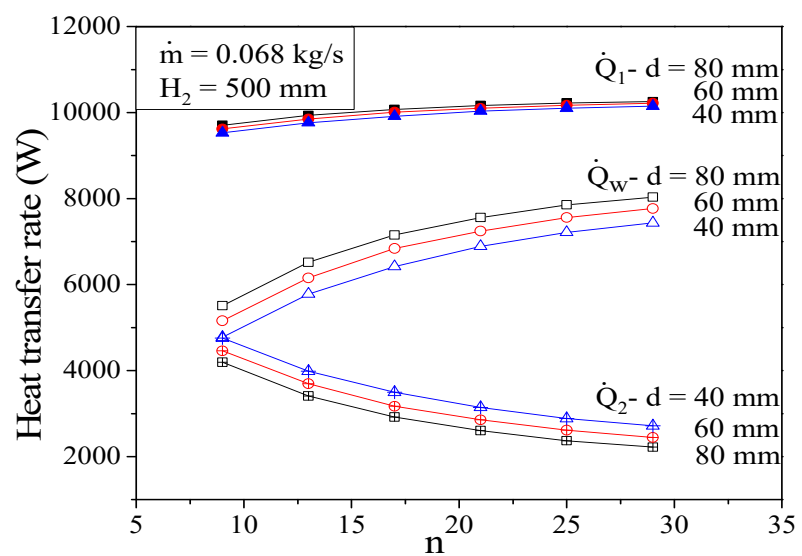

Fig. 6. Heat transfer rate with $\dot{m}=0.068 \mathrm{~kg} / \mathrm{s}$ and variable $V_{f}$. 


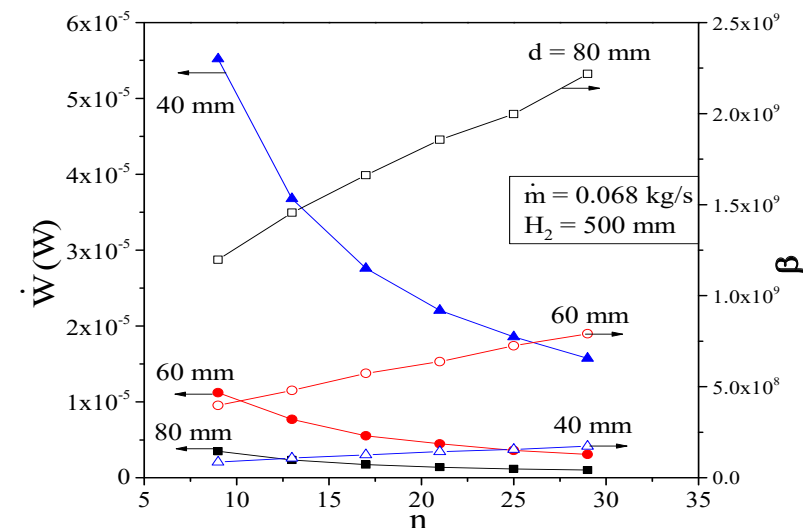

Fig. 7. Power consumption and heat-to-work ratio with $\dot{m}=0.068 \mathrm{~kg} / \mathrm{s}$ and variable $V_{f}$.

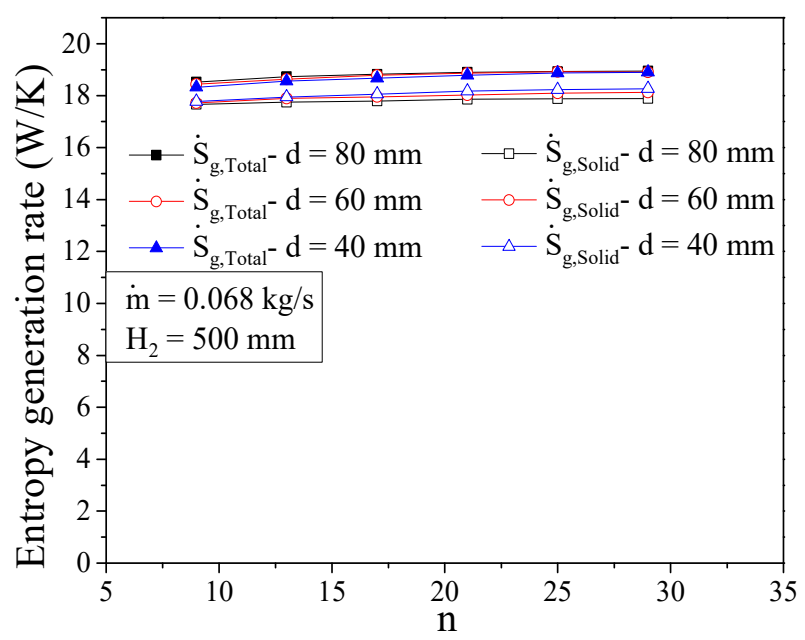

Fig. 8. Entropy generation rate with $\dot{m}=0.068 \mathrm{~kg} / \mathrm{s}$ and variable $V_{f}$.

\subsection{Effects of variable $n$ or $d$ with fixed $V_{f}$}

In Section 4.1, $V_{f}$ changes with the variation of $d$ or $n$. In this paper, the cooling channels are pure fluid space, not formed by buried pipes (metal or non-metal). Therefore, in real designs, larger $V_{f}$ will weaken the mechanical strength of the foundation. This means that the design needs a trade-off between the heat transfer design and the mechanical design. In this section, we consider the design with fixed volume $V_{f}$ and explore the effects of $n$ (or $d$ ). Here $n$ and $d$ are dependent, and larger $n$ corresponds to smaller $d$, different from that in Section 4.1. Figures 9-11 show the effects of $n$ for $V_{f}=0.3374 \mathrm{~m}^{3}$ (i.e., the case $n=$ 12 and $d=80 \mathrm{~mm}$ in Section 4.1). For fixed $V_{f}$, when $n$ increases, due to larger $A$ and smaller $d$, both the heat removal $\dot{Q}_{w}$ and the power consumption $\dot{W}$ increase, and $\dot{Q}_{2}$ decreases. For $n \geq 33$, the increasing of $\dot{Q}_{w}$ slows down, meaning that more cooling channels are unnecessary. Figure 11 shows the variation of $\dot{S}_{g, \text { Total }}$ and $\dot{S}_{g, \text { Solid }}$ is very limited.

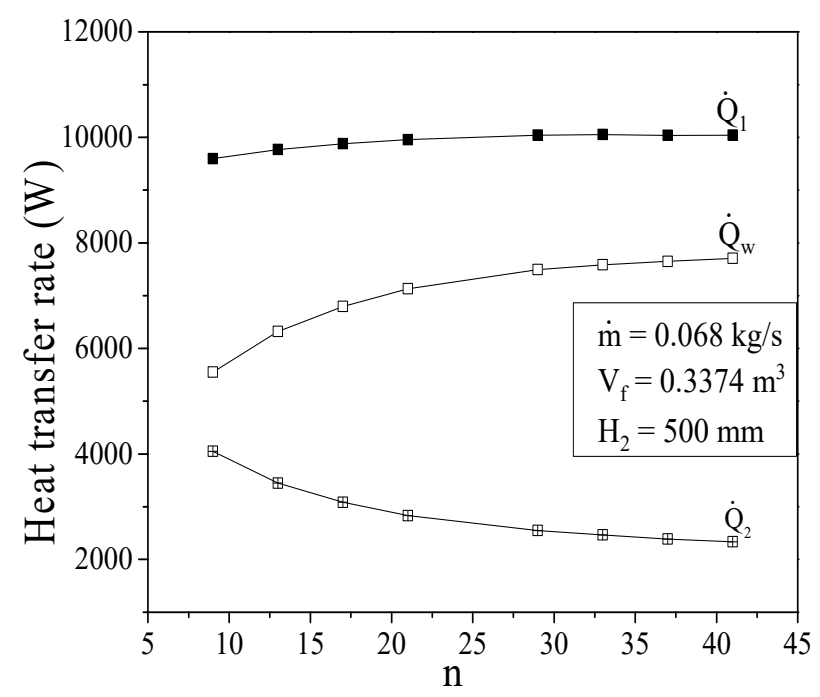

Fig. 9. Heat transfer rate with fixed $V_{f}$.

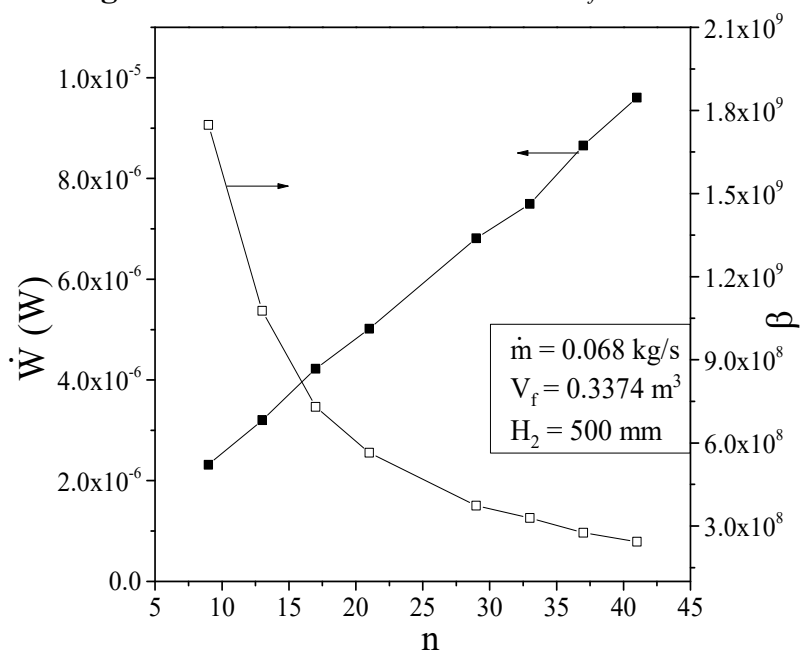

Fig. 10. Power consumption and heat-to-work ratio with fixed $V_{f}$.

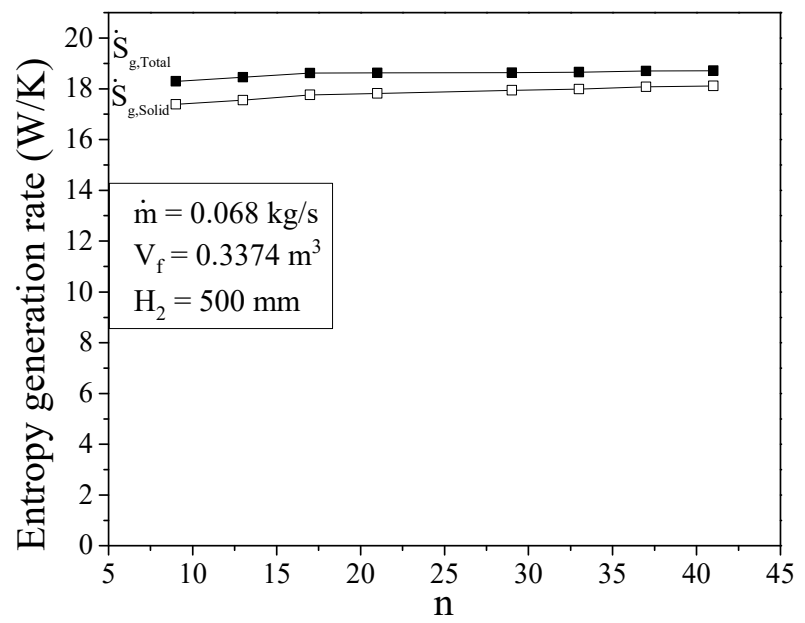

Fig. 11. Entropy generation rate distribution with fixed $V_{f}$.

Figure 12 shows the fields of pressure, temperature and entropy generation rate of two designs (i.e., with cooling channels and without cooling channels) at the cross section $y=250 \mathrm{~mm}$ (mid position of the concrete in $y$ direction). The cross section can be divided into two 
regions: the center region (inner cycle part with diameter $\left.D_{1}\right)$ and the non-center region. In Figure 12a, the pressure distribution is the same for different channels, but in Figure 12c, the temperature distribution is not the same for different channels. The outlet temperatures at the outlets of the channels for Figure 12c are documented in Figure 13. The channels near the center of the concrete remove more heat. Considering this cooling nonuniformity, it is possible to use multi-diameter design (e.g., constructal design) to improve the heat removal capability ${ }^{[25]}$. In Figure $12 \mathrm{c}$, the average temperature in the concrete domain is lower than that without cooling channels shown in Figure 12d, which is also an advantage of the foundation cooling. In addition, due to the cooling effect, the temperature outside the center region is also influenced more or less through heat conduction in the concrete.

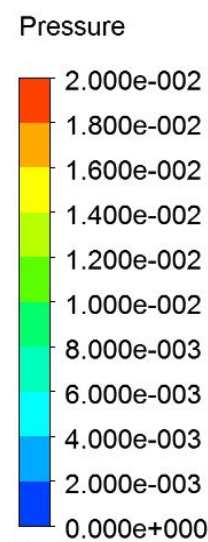

[Pa]

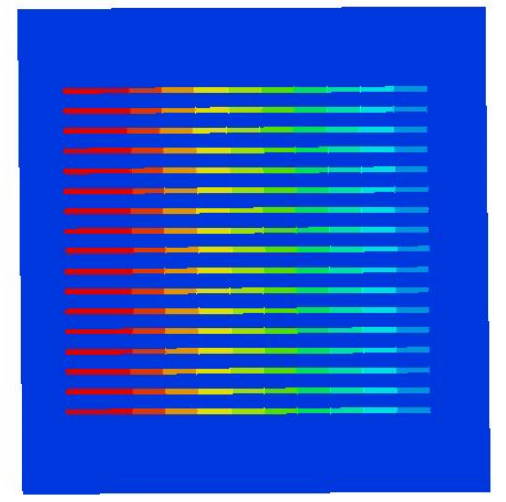

(a)

Temperature

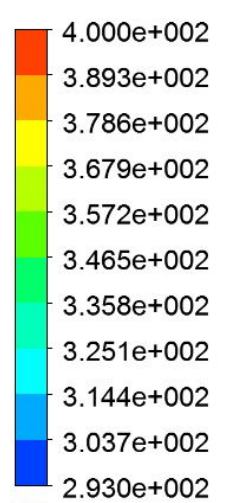

[K]

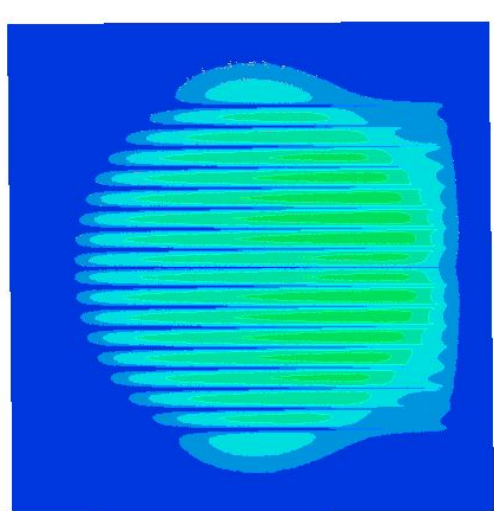

(c)

From Figures 12e and $\mathrm{f}$, we see that the entropy generation rate distribution in the center domain of Figure $12 \mathrm{f}$ is more uniform due to the lack of cooling channels. In Figure 12e, the local entropy generation rate $\dot{s}_{g}^{\prime \prime \prime}$ is larger near the fluid-solid interfaces mainly because of larger temperature difference (temperature gradient). The largest $\dot{s}_{g}^{\prime \prime \prime}$ for the two designs is different. For example, the largest $\dot{s}_{g}^{\prime \prime \prime}$ is about $20.1 \mathrm{~W} /\left(\mathrm{m}^{3} \mathrm{~K}\right)$ in Figure $12 \mathrm{e}$ and $3.72 \mathrm{~W} /\left(\mathrm{m}^{3} \mathrm{~K}\right)$ in Figure 12f. Through integration, we can also obtain the entropy generation rates of the solid domain and the fluid domain: $\dot{S}_{g, \text { Solid }}=17.75 \mathrm{~W} / \mathrm{K}$ and $\dot{S}_{g, \text { Fluid }}=1.028 \mathrm{~W} / \mathrm{K}$. Here $\dot{S}_{g, \text { Solid }}$ is dominant which has been remarked in Section 4.1.

\section{Pressure

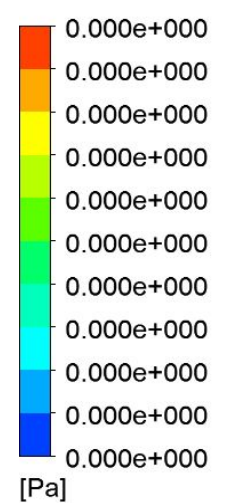

Temperature

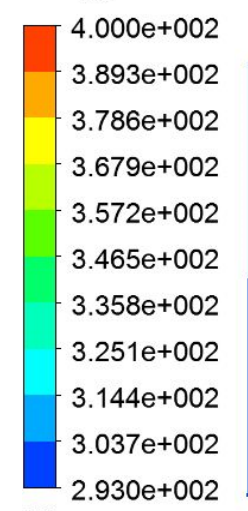

[K]

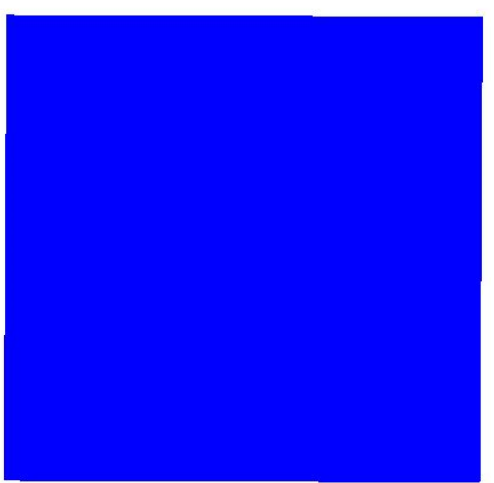

(b)

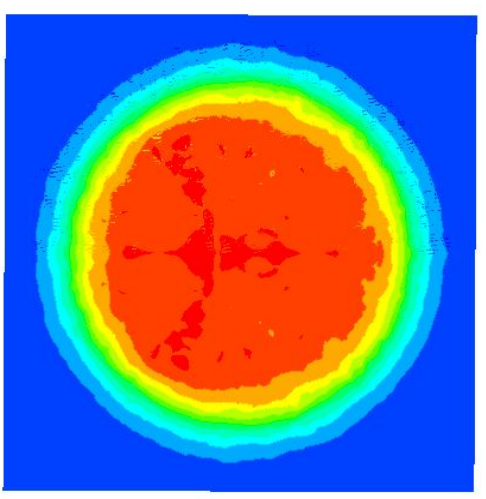

(d) 
Entropy Generation Rate

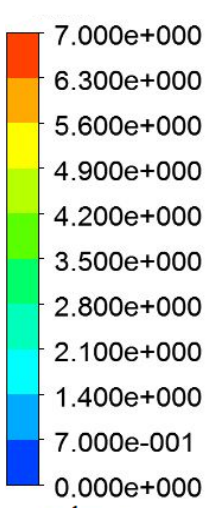

$\left[\mathrm{WK}^{-1} \mathrm{~m}^{-3}\right.$ ]

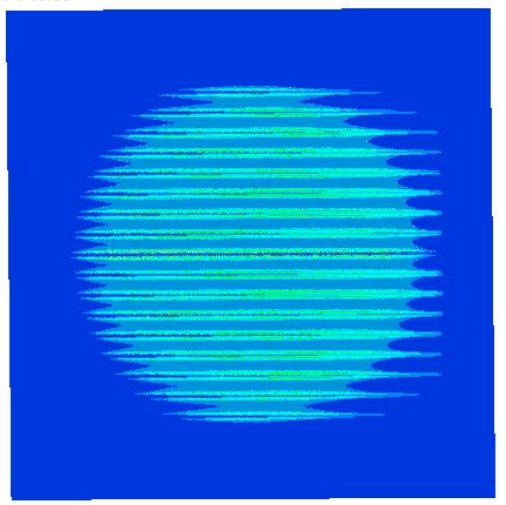

(e)
Entropy Generation Rate

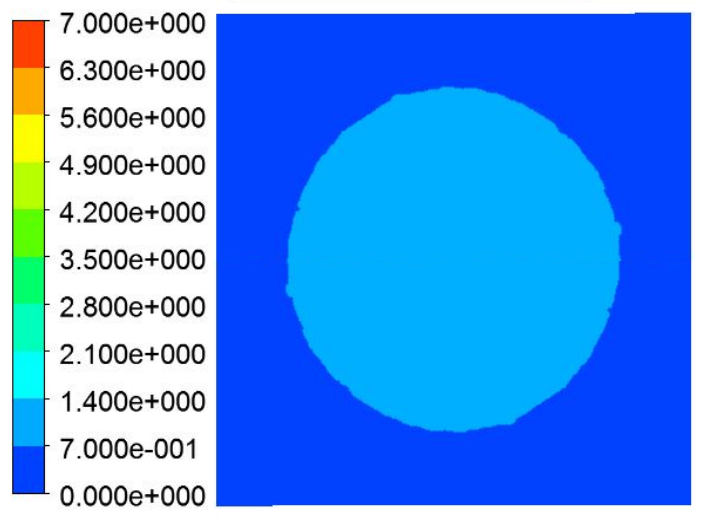

$\left[\mathrm{WK}^{-1} \mathrm{~m}^{-3}\right.$ ]

Fig. 12. Fields of pressure, temperature and entropy generation rate with $y=250 \mathrm{~mm}, d=80 \mathrm{~mm}$, and $\dot{m}=0.068 \mathrm{~kg} / \mathrm{s}$ : (a) with channels: pressure; (b) without channels: pressure; (c) with channels: temperature; (d) without channels: temperature; (e) with channels: entropy generation rate; (f) without channels: entropy generation rate.

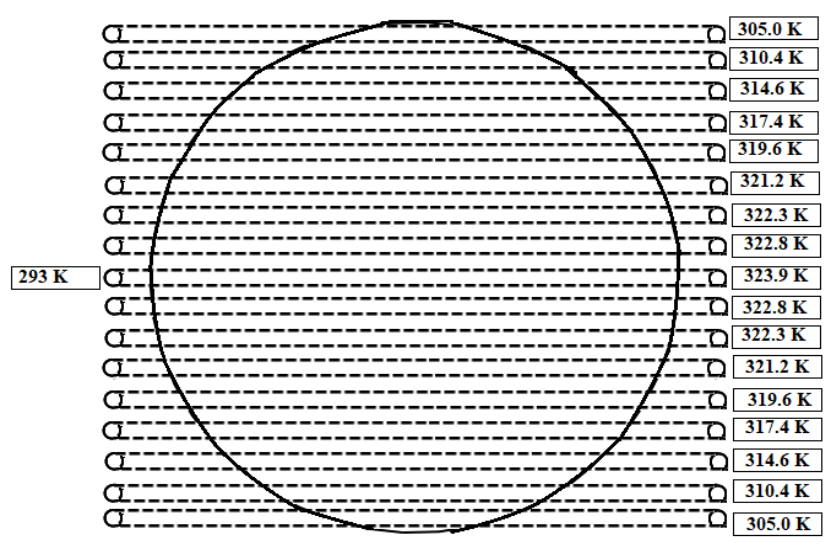

Fig. 13. Temperatures at the outlets of the cooling channels with $d=80 \mathrm{~mm}, n=17$ and $\dot{m}=0.068$ $\mathrm{kg} / \mathrm{s}$.

\subsection{Effects of internal fins in the cooling channels}

Figure 14 shows the comparison between the design with internal fins and the reference design (without internal fins) for $d=80 \mathrm{~mm}$ and $n=17$. Seen in Figure 14, $\dot{Q}_{2}$ of the design with fins is significantly lower than that of the reference design. This is the obvious advantage of the design with fins. When $\dot{m}$ increases, the gap between the two designs for both $\dot{Q}_{w}$ and $\dot{Q}_{2}$ narrows. Figure 15 tells that the power consumption for the design with fins is higher due to more flow friction of the fins. With the increasing in $\dot{m}$, the power consumption gap between the two designs expands. In the specified range, the heat-towork ratio is still very high. For instance, when $\dot{m}=$ $0.102 \mathrm{~kg} / \mathrm{s}, \beta=1.24 \times 10^{8}$ and $6.1 \times 10^{8}$ for the design with fins and without fins, respectively.

Figure 16 shows that the design with fins produces slightly higher irreversibility than the reference design.
For example, when $\dot{m}=0.068 \mathrm{~kg} / \mathrm{s}, \quad \dot{S}_{g, \text { Total }}$ is 19.506 $\mathrm{W} / \mathrm{K}$ for the design with fins and $18.778 \mathrm{~W} / \mathrm{K}$ for the reference design. Although the fins increase flow friction, the flow friction irreversibility is still negligible. The observation in Figures 14-16 tells us that adding fins for laminar flow is an efficient way to enhance the cooling effect and weaken the heat leakage to the ground.

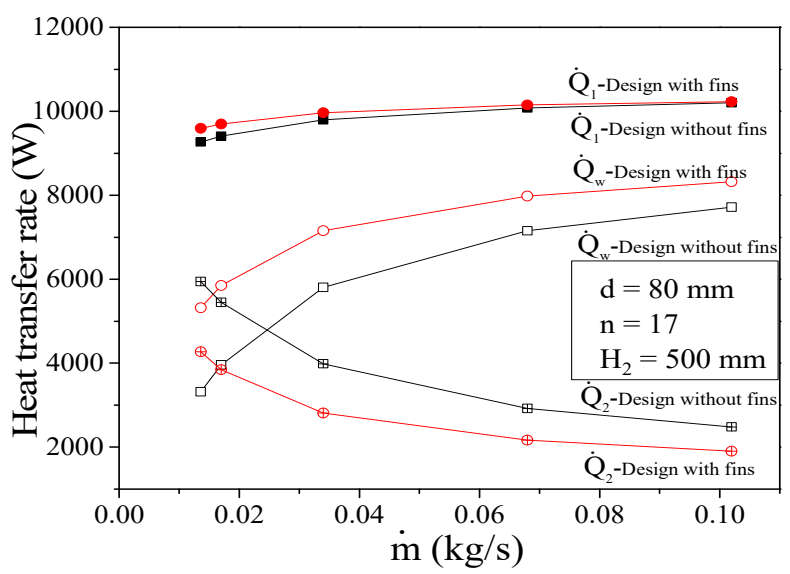

Fig. 14. Heat transfer rate for the design with fins with $d$ $=80 \mathrm{~mm}$ and $n=17$.

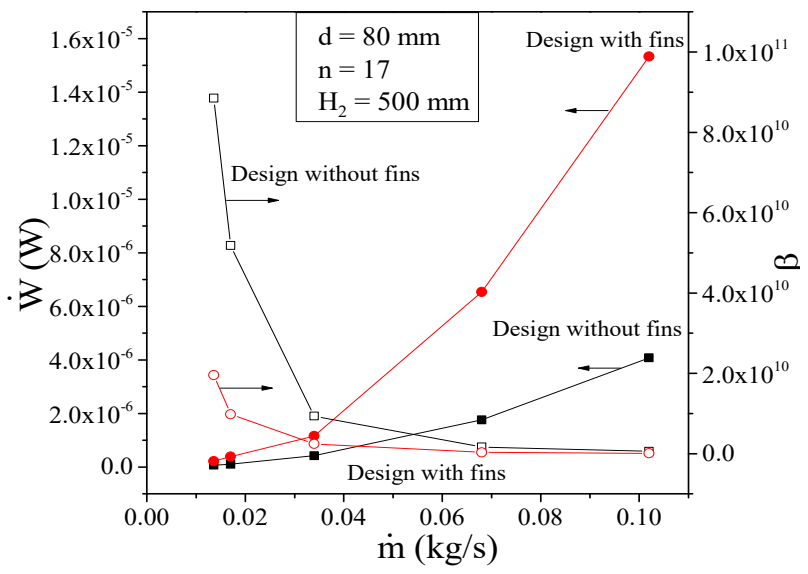

Fig. 15. Power consumption and heat-to-work ratio for the design with fins with $d=80 \mathrm{~mm}$ and $n=17$. 


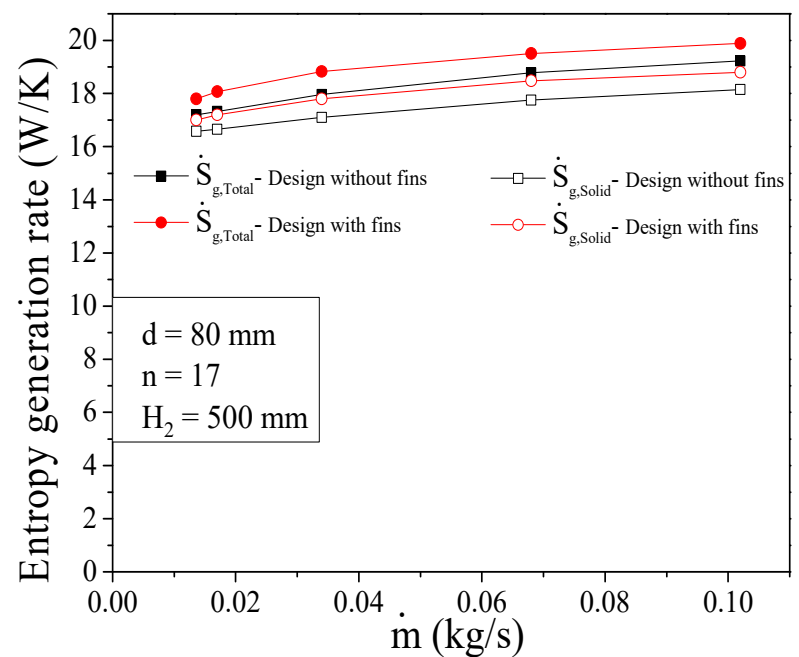

Fig. 16. Entropy generation rate for the design with fins with $d=$ $80 \mathrm{~mm}$ and $n=17$.

\subsection{Effects of the insulation thickness}

In Sections 4.1-4.3, the thickness of the insulation layer $\left(\mathrm{H}_{2}\right)$ is fixed. Here we discuss its impacts. Figure 17 shows that both $\dot{Q}_{1}, \dot{Q}_{2}$ and $\dot{Q}_{w}$ decrease with increase in $\mathrm{H}_{2}$.Actually, when $\mathrm{H}_{2}$ increases, the average temperature difference between the fluid and the concrete is reduced, which leads to poor cooling effect. Because of constant cooling channels and water flow rate, the power consumption does not change while the heat-to-work ratio decreases with the increasing in $\mathrm{H}_{2}$, shown in Figure 18. Figure 19 shows that $\dot{S}_{g, \text { Total }}$ decreases with the increasing in $H_{2}$ due to the reduced $\frac{\dot{Q}_{2}}{T_{2}}$ and $\dot{m}\left(s_{\text {out }}-s_{\text {in }}\right)$. In the range $H_{2}=200-1000 \mathrm{~mm}$, the entropy generation rate in the solid domain is dominant. Although increasing the thickness of the insulation layer leads to less heat leakage to the ground and less irreversibility, the price in investment and size and the effect on the mechanical design are critical concerns.

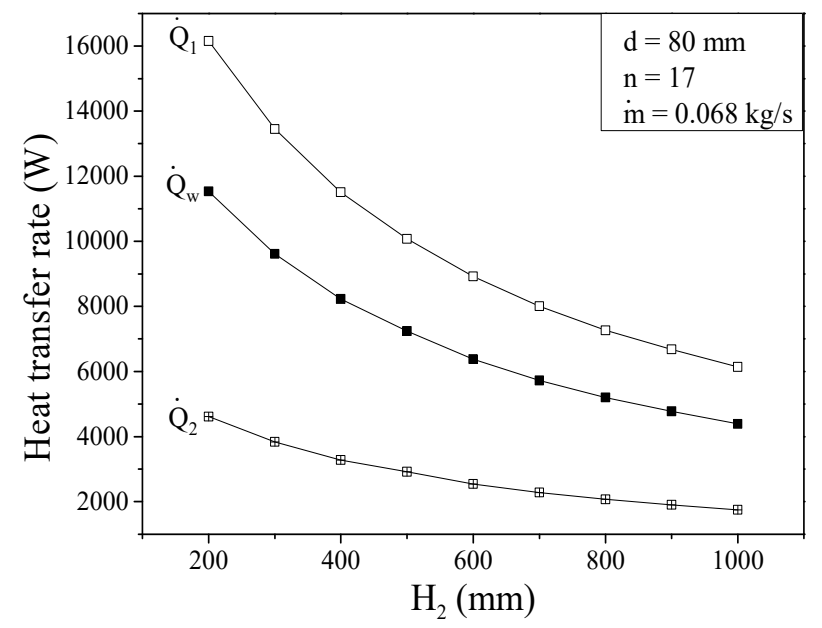

Fig. 17. Heat transfer rate for different thickness of the insulation layer with $d=80 \mathrm{~mm}, n=17$ and $\dot{m}=$ $0.068 \mathrm{~kg} / \mathrm{s}$.

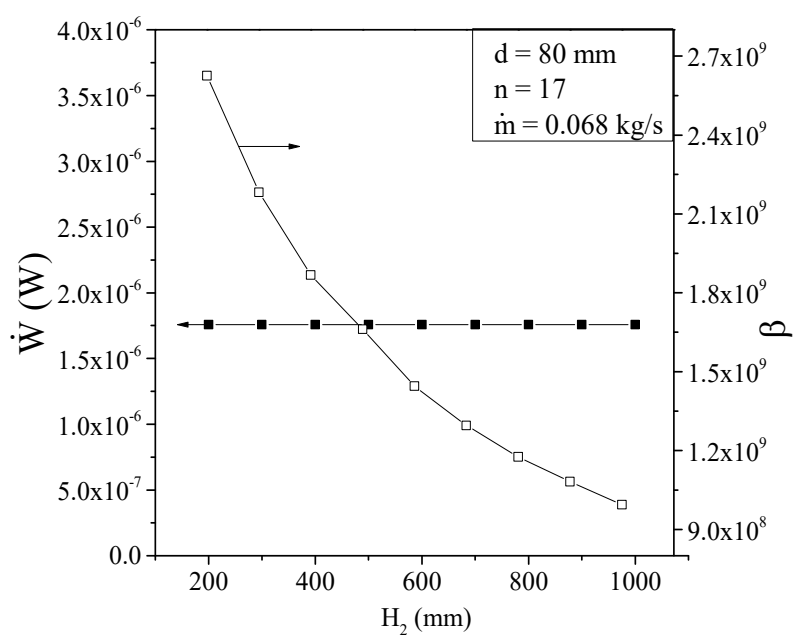

Fig. 18. Power consumption and heat-to-work ratio for different thickness of the insulation layer with $d=80$ $\mathrm{mm}, n=17$ and $\dot{m}=0.068 \mathrm{~kg} / \mathrm{s}$.

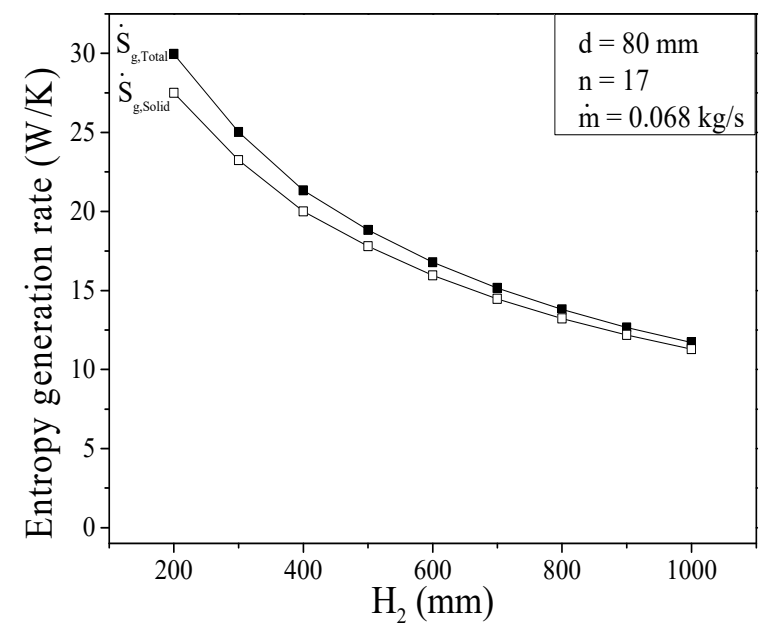

Fig. 19. Entropy generation rate for different thickness of the insulation layer with $\mathrm{d}=80 \mathrm{~mm}, \mathrm{n}$ $=17$ and $\dot{m}=0.068 \mathrm{~kg} / \mathrm{s}$.

\subsection{Turbulent flow}

Increasing the fluid flow velocity is an efficient way to enhance heat transfer with the price of more power consumption. Figures 20-22 provide examples of turbulent flow in the cooling channels with $d=80 \mathrm{~mm}$ and $n=17$. The Reynolds number ranges from 3174 and 95207. According to Figure 20, when $\dot{m}$ is larger than about $34 \mathrm{~kg} / \mathrm{s}, \dot{Q}_{w}$ and $\dot{Q}_{2}$ vary very slowly. Higher velocity is meaningless in enhancing the cooling effect. Higher flow rate leads to significantly increased power consumption, much larger than that for laminar flow. Here when $\dot{m}=34 \mathrm{~kg} / \mathrm{s}, \beta=89$, which is much less than that for laminar flow (Figure 21). Figure 22 shows the variation trend of the total entropy generation rate versus 
the flow rate. Both $\dot{S}_{g, \text { Total }}$ and $\dot{S}_{g, \text { Solid }}$ for turbulent flow are larger than that for laminar flow. Although turbulent flow needs more power consumption, the flow friction irreversibility still amounts for a very small fraction in $\dot{S}_{g, \text { Total }}$. For example, $\dot{m}=34 \mathrm{~kg} / \mathrm{s}$, the flow friction irreversibility $\dot{S}_{g, F l u i d, \triangle P}$ is only about $0.05 \mathrm{~W} / \mathrm{K}$.

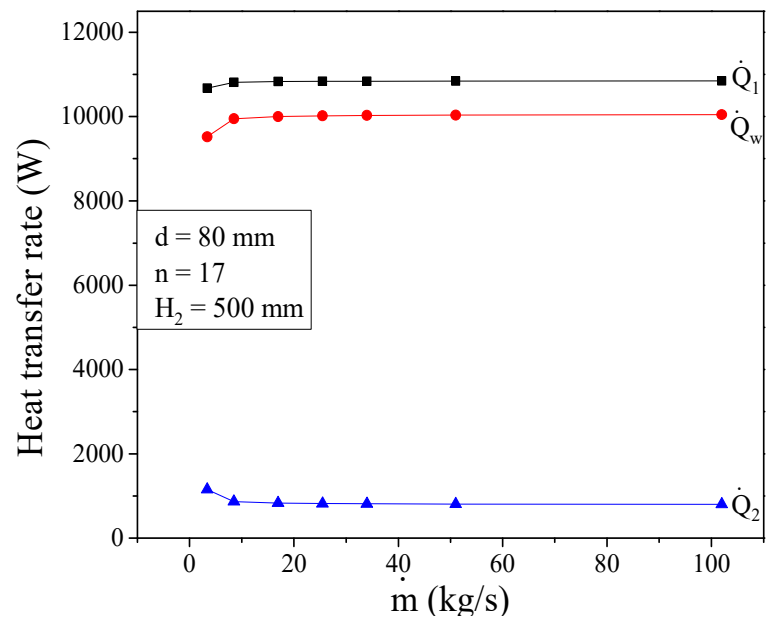

Fig. 20. Heat transfer rate for turbulent flow with $d$ $=80 \mathrm{~mm}$ and $n=17$.

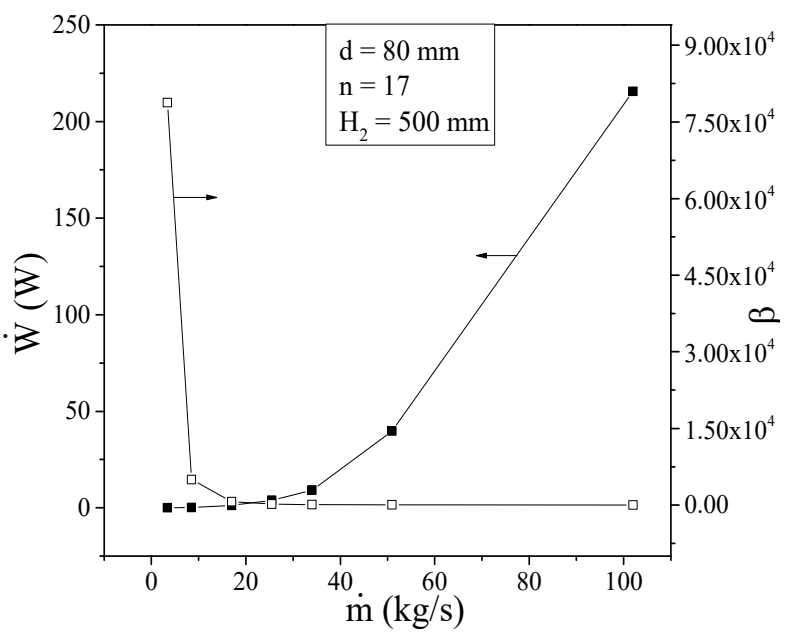

Fig. 21. Power consumption and heat-to-work ratio for turbulent flow with $d=80 \mathrm{~mm}$ and $n=17$.

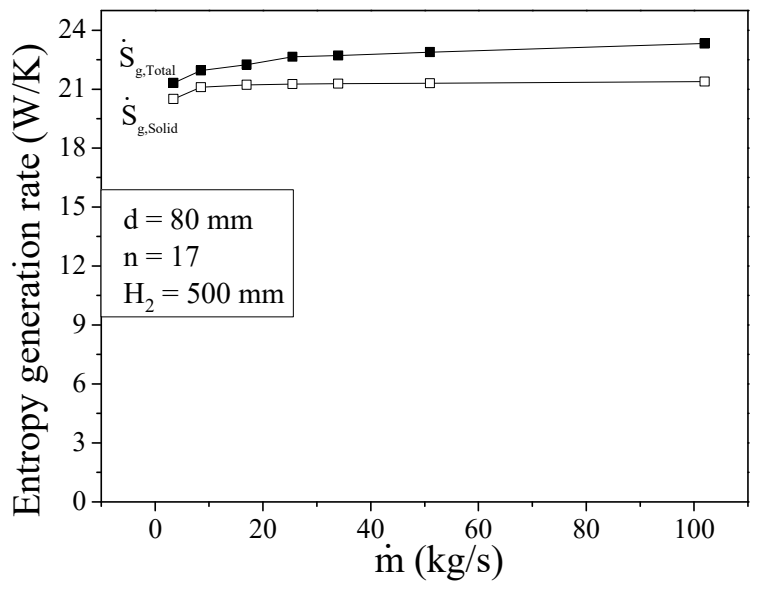

Fig. 22. Entropy generation rate for turbulent flow with $d$ $=80 \mathrm{~mm}$ and $n=17$.

\subsection{Further Discussion}

In the above sections, we discussed different ways to reduce the heat leakage to the ground based on foundation cooling. Parametric analysis was performed for the specified height position of the cooling channels (defined by the value of $y$ ). If the cooling channels are moved closer toward the top side (i.e., the hot side), the cooling effect becomes stronger and the heat leakage is less due to larger temperature difference between the solid and the fluid. For example, under the conditions $d=80 \mathrm{~mm}, n=$ 17 and $\dot{m}=0.068 \mathrm{~kg} / \mathrm{s}, \dot{Q}_{2}=2920 \mathrm{~W}$ and $\dot{S}_{g, \text { Total }}=18.78$ $\mathrm{W} / \mathrm{K}$ for $y=250 \mathrm{~mm}$, while $\dot{Q}_{2}=2390 \mathrm{~W}$ and $\dot{S}_{g, \text { Total }}=$ $21.97 \mathrm{~W} / \mathrm{K}$ for $y=400 \mathrm{~mm}$. It should be noted that the position of the cooling channels affects the mechanical strength which should be considered in real designs.

In this paper, we assumed steady heat transfer from the molten salt tank foundation to the ground. Because the heat accumulation in the ground is very slow, steady assumption is acceptable for foundation cooling design. If quantitative analysis on long-term operation safety is concerned, a dynamic heat accumulation model coupled with the ground is helpful.

\section{Conclusions}

In this paper, by using widely-accepted CFD technique for single-phase flow and heat transfer, we investigated the fluid flow, heat transfer and entropy generation rate for molten salt tank foundation with water cooling channels. We observed that both laminar and turbulent flow cooling can reduce the heat leakage to the ground and the average temperature in the concrete significantly, while the power consumption for laminar flow is negligible. The effects of the volume of the cooling channels are explored and proper designs are recommended. Incorporating internal fins into the cooling channels is an efficient way to decrease the heat leakage to the ground.

The total and local entropy generation rates were documented. For the specified conditions in this paper, the total entropy generation rate with foundation cooling is higher than that without foundation cooling. The entropy generation rate in the solid domain is dominant and the flow friction irreversibility in the fluid domain is negligible. Larger insulation layer thickness reduces the heat leakage to the ground and the total entropy generation rate simultaneously with the price in investment, size and different mechanical design. From the local entropy generation rate map, we can identify where the most irreversibility is produced. The largest entropy generation rate for the design with foundation cooling occurs near the solid-fluid interfaces and is much higher than that without foundation cooling.

The present work reveals the characteristics of the molten salt tank foundation with internal water cooling from the viewpoints of both the first and the second laws. The work identifies the important factors that influence 
the heat leakage to the ground, the power consumption needed and the entropy generation rate produced, which deepens our understanding of the heat transfer process for molten salt tank foundation and can help us make decisions in the process of equipment design.

\section{References}

1. H.P. Garg, S.C. Mullick, A.K. Bhargava, Solar Thermal Energy Storage (D. Reidel Publishing Company: AA Dordrecht, Holland, 1985).

2. A. Sharma, V. V. Tyagi, C.R. Chen, D. Buddhi, Review on thermal energy storage with phase change materials and applications. Renew. Sustain. Energy Rev. 13, 318-345 (2009).

3. I. Sarbu, C. Sebarchievici, A comprehensive review of thermal energy storage. Sustainability 10, 191 (2018).

4. K. Zhang, J. Du, X. Liu, H. Zhang, Molten salt flow and heat transfer in paddle heat exchangers. Int. J. Heat Technol. 34, 43-50 (2016).

5. Vignarooban, K.; Xu, X.; Arvay, A.; Hsu, K.; Kannan, A.M. Heat transfer fluids for concentrating solar power systems - A review. Appl. Energy 146, 383396 (2015).

6. J. Ding, X. Wei, Q. Peng, and J. Yang, Medium and High Temperature Heat Transfer and Storage Materials (Science Press: Beijing, China, 2013). (In Chinese)

7. M. Castro, J.L. Presa, J. Díaz, J. Peire, A.F. Baker, S.E. Faas, L.G. Radosevich, A.C. Skinrood, C.R.S. receiver and storage systems evaluation. Sol. Energy 47, 197-207 (1991).

8. R.W. Bradshaw, D.B. Dawson, W. De la Rosa, R. Gilbert, S.H. Goods, M.J. Hale, P. Jacobs, S. a. Jones, G.J. Kolb, J.E. Pacheco, M.R. Prairie, H.E. Reilly, S.K. Showalter, L.L. Vant-Hull, Final Test and Evaluation Results from the Solar Two Project (SAND2002-0120, Sandia National Laboratories: California, USA, 2002).

9. U. Herrmann, B. Kelly, H. Price, Two-tank molten salt storage for parabolic trough solar power plants. Energy 29, 883-893 (2004).

10. J. Schulte-Fischedick, R. Tamme, U. Herrmann, CFD analysis of the cool down behaviour of molten salt thermal storage systems (ASME: New York, NY, USA, 2008).

11. R. Gabbrielli, C. Zamparelli, Optimal design of a molten salt thermal storage tank for parabolic trough solar power plants. J. Sol. Energy Eng. 131, 041001104100110 (2009).

12. F. Zaversky, J. García-Barberena, M. Sánchez, D. Astrain, Transient molten salt two-tank thermal storage modeling for CSP performance simulations. Sol. Energy 93, 294-311 (2013).

13. I. Rodríguez, C.D. Pérez-Segarra, O. Lehmkuhl, A. Oliva, Modular object-oriented methodology for the resolution of molten salt storage tanks for CSP plants. Appl. Energy 109, 402-414 (2013).

14. C. Prieto, L. Miró, G. Peiró, E. Oró, A. Gil, L.F. Cabeza, Temperature distribution and heat losses in molten salts tanks for CSP plants. Sol. Energy 135, 518-526 (2016).

15. C. Prieto, R. Osuna, A.I. Fernández, L.F. Cabeza, Molten salt facilities, lessons learnt at pilot plant scale to guarantee commercial plants; heat losses evaluation and correction. Renew. Energy 94, 175185 (2016).

16. J. Bonilla, M.M. Rodríguez-García, L. Roca, de la A. Calle, L. Valenzuela, Design and experimental validation of a computational effective dynamice thermal energy storage tank model. Energy 152, 840857 (2018).

17. Z. Liu, J. Yan, P. Gao, H. Tan, Experimental study on temperature distribution in an ice-making machine multichannel evaporator. Sci. Technol. Built Environ. 25, 69-82 (2019).

18. Z. Wan, J. Wei, M.A. Qaisrani, J. Fang, N. Tu, Evaluation on thermal and mechanical performance of the hot tank in the two-tank molten salt heat storage system. Appl. Therm. Eng. 167, 114775 (2020).

19. C. Prieto, S. Fereres, F.J. Ruiz-Cabañas, A. Rodriguez-Sanchez, C. Montero, Carbonate molten salt solar thermal pilot facility: Plant design, commissioning and operation up to $700{ }^{\circ} \mathrm{C}$. Renew. Energy 151, 528-541 (2020).

20. A. Bejan, Second-Law Analysis in Heat Transfer and Thermal Design. Adv. Heat Transf. 15, 1-58 (1982).

21. S.B. Pope, Turbulent Flows, 1st ed. (Cambridge University Press \& Beijing World Publishing Corporation: Cambridge, UK, 2010).

22. Z. Yang, S. V. Garimella, Molten-salt thermal energy storage in thermoclines under different environmental boundary conditions. Appl. Energy 87, 3322-3329 (2010).

23. C. Xu, X. Li, Z. Wang, Y. He, F. Bai, Effects of solid particle properties on the thermal performance of a packed-bed molten-salt thermocline thermal storage system. Appl. Therm. Eng. 57, 69-80 (2013).

24. ANSYS Fluent. User's Manual, version 14.5 (Fluent Inc: Canonsburg, Pennsylvania, United States 2012).

25. A. Bejan, S. Lorente, Design with Constructal Theory (Wiley \& Sons Inc.: Hoboken, NJ, USA, 2008). 